\title{
Deletion of the Nucleotide Exchange Factor Vav3 Enhances Axonal Complexity and Synapse Formation but Tampers Activity of Hippocampal Neuronal Networks In Vitro
}

\author{
David Wegrzyn ${ }^{1}$, Christine Wegrzyn ${ }^{1}$, Kerry Tedford ${ }^{2}$, Klaus-Dieter Fischer ${ }^{2}$ and \\ Andreas Faissner 1,*(D)
}

1 Department of Cell Morphology and Molecular Neurobiology, Ruhr-University Bochum, Universitaetsstr. 150, Ruhr-University, D-44801 Bochum, Germany; David.Wegrzyn@rub.de (D.W.); Christine.Gottschling@rub.de (C.W.)

2 Institute of Biochemistry and Cell Biology, OVGU University of Magdeburg, Leipziger Str. 44, D-39120 Magdeburg, Germany; kerry.tedford@med.ovgu.de (K.T.); klaus.fischer@med.ovgu.de (K.-D.F.)

* Correspondence: andreas.faissner@rub.de; Tel.: +49-234-3223851

Received: 18 November 2019; Accepted: 23 January 2020; Published: 28 January 2020

\begin{abstract}
Vav proteins activate GTPases of the RhoA subfamily that regulate the cytoskeleton and are involved in adhesion, migration, differentiation, polarity and the cell cycle. While the importance of RhoA GTPases for neuronal morphology is undisputed, their regulation is less well understood. In this perspective, we studied the consequences of the deletion of $\operatorname{Vav} 2, \operatorname{Vav} 3$ and $\operatorname{Vav} 2$ and $3\left(\operatorname{Vav} 2^{-1-}\right.$, $\left.\mathrm{Vav}^{-I^{-}}, \mathrm{Vav}^{-/-} / 3^{-/-}\right)$for the development of embryonic hippocampal neurons in vitro. Using an indirect co-culture system of hippocampal neurons with primary wild-type (WT) cortical astrocytes, we analysed axonal and dendritic parameters, structural synapse numbers and the spontaneous network activity via immunocytochemistry and multielectrode array analysis (MEA). Here, we observed a higher process complexity in $\mathrm{Vav}^{-/-}$, but not in $\mathrm{Vav}^{-{ }^{--}}$neurons after three and five days in vitro (DIV). Furthermore, an enhanced synapse formation was observed in $\mathrm{Vav}^{-/-}$after 14 days in culture. Remarkably, $\mathrm{Vav} 2^{-/-} / 3^{-/-}$double knockout neurons did not display synergistic effects. Interestingly, these differences were transient and compensated after a cultivation period of 21 days. Network analysis revealed a diminished number of spontaneously occurring action potentials in $\mathrm{Vav}^{-1-}$ neurons after 21 DIV. Based on these results, it appears that Vav3 participates in key events of neuronal differentiation.
\end{abstract}

Keywords: axon growth; dendrite growth; guanine nucleotide exchange factor; Vav proteins; MAP2; multielectrode array (MEA); Rac1; RhoA family; Tau

\section{Introduction}

The Vav subfamily of guanine nucleotide exchange factors (GEFs) is composed of the three members Vav1, Vav2 and Vav3 [1]. While the expression of Vav1 is strictly limited to the hematopoietic system [2-4], Vav2 and Vav3 are also expressed in non-hematopoietic tissues and can be detected in the central nervous system (CNS) [5,6]. Vav proteins are regulated by receptor tyrosine kinases and activate their target proteins by catalysing the exchange of GDP by GTP [6,7]. In this way Vav proteins can activate members of the Rho GTPase family. Interestingly, GDP/GTP binding experiments could show that Vav proteins activate specifically RhoA, RhoG and Rac1 but not Cdc42 [8]. However, there are indications that Cdc42 is also influenced by Vav2 and Vav3 through an accumulation of phosphatidylinositol 3,4,5-trisphosphate [9]. 
Rho GTPases and their regulators participate in the development and plasticity of the CNS and are crucial for the organization of the cytoskeleton [10-13]. RhoA for example is involved in the semaphorin3a induced growth cone collapse of neurons [14]. In addition, experiments with dominant negative forms of Rac1 and Cdc42 showed a reduction of primary dendrites in multipolar neurons and basal dendrites in pyramidal neurons in rats [15]. Vav proteins act as activators of Rho GTPases and could exert an important regulatory function for the translation of extracellular signals into modifications of the cytoskeleton $[11,16]$. With regard to axonal growth, it was observed that Vav2/3-deficient retinal ganglion cells fail to collapse their growth cone after ephrin-A stimulation in vitro [17]. Furthermore, an induction gene trap screening revealed a correlation between the repulsive extracellular matrix protein tenascin- $C$ and the upregulation of Vav3 in neural stem cells $[18,19]$. There are several studies indicating that a lack of Vav proteins leads to disturbances in the development of the CNS. The knockout of Vav3 resulted in less branched Purkinje and granule cells in the cerebellum and led to motor deficiencies during the postnatal period. These deficits vanished in the adult stage [20]. Interestingly, the depletion of Vav2 did not produce these abnormalities. Moreover, Vav3 is necessary for the correct axonal guidance of GABAergic neurons in the brainstem and thus responsible for physiologic cardiovascular and renal functions [21,22]. Recent studies revealed a connection between polymorphisms in the VAV2 and the VAV3 genes and cardiovascular risk factors [23]. Furthermore, a Japanese genome-wide association study could demonstrate that mutations in the VAV3 gene seem to be associated with a higher risk for schizophrenia [24].

Experiments with in situ hybridizations demonstrated high mRNA levels of Vav2 and Vav3 in the hippocampus of mice (Allen Mouse Brain Atlas, http://www.brain-map.org) [25,26]. Along these lines, a comprehensive transcriptome analysis has demonstrated the expression of both Vav2 and Vav3 in CNS neurons [27]. In contrast $\operatorname{Vav} 1$ is absent from neurons and glial cell types but abounds in mesodermally derived microglia [27]. Consistent with these observations, Vav3 has been documented in the growth cones of cultured hippocampal neurons after five days in vitro [22]. However, little is known about the function of Vav proteins for the early development and synaptogenesis of hippocampal neurons. Therefore, we cultured hippocampal neurons lacking Vav2, Vav3 and Vav2/3 in the presence of native cortical astrocytes in a co-culture setup. This system allows the cultivation of neuronal networks in completely defined medium and the subsequent analysis of structural synapses in vitro [28-31]. In this model, we first assessed the morphological differentiation of axons and dendrites using specific markers. In addition, multi-electrode array analysis [32] was performed to measure the spontaneous network activity of wild-type and $\operatorname{Vav} 3^{-/-}$neurons.

\section{Results}

In view of the importance of small GTPases of the RhoA family for neuronal differentiation, we sought to determine the impact of the guanine nucleotide exchange factors Vav2 and Vav3 on neuronal morphology. We cultivated the neurons of one wild-type and three mutant $\left(\operatorname{Vav}^{-1-}, \operatorname{Vav}^{-1-}\right.$ and Vav $2^{-I-} / 3^{-I-}$ ) mouse lines in the presence of primary wild-type cortical astrocytes in order to guarantee identical culture conditions. Thus, any difference emerging in the neuronal monolayer of our cell culture system should be the direct expression of changes in the genotype caused by the deletion of the respective Vav genes. With this aim, hippocampal wild-type and knockout neurons were cultured for 3 or 5 DIV and immunostained with antibodies against the microtubule associated proteins MAP2 and Tau. While the expression of MAP2 is limited to the dendritic compartment [33], Tau proteins highly accumulate in the axon and take part in its stabilization [34]. Therefore, these markers are excellently suited to study the establishment of neuronal polarity

\subsection{Ablation of Vav3 Increases Axonal Complexity and Dendritic Length after 3 and 5 DIV without Affecting the Number of Dendrites}

The distribution of MAP2 and Tau allowed for a differential analysis of axonal and dendritic parameters of wild-type, $\operatorname{Vav}^{-/-}, \mathrm{Vav}^{-/-}$and $\mathrm{Vav}^{-/-} / 3^{-/-}$neurons (Figures 1 and 2). After a 
cultivation time of 3 days, neurons developed well-defined dendrites and axons (Figure 1a-d). Based on the immunocytochemical staining, slight differences in the complexity of $\mathrm{Vav}^{-/-}$and $\mathrm{Vav}^{-1-} \mathrm{3}^{-1-}$ neurons could be observed. Thus, dendrites and axons of $\operatorname{Vav}^{-/-}$and $\operatorname{Vav}^{-/-} / 3^{-/-}$neurons appeared longer and more complex compared with axons and dendrites of wild-type and $V a v 2^{-/-}$neurons (Figure 1b,d). In contrast wild-type and Vav2 $2^{-/-}$neurons showed a similar morphology (Figure 1a,c).

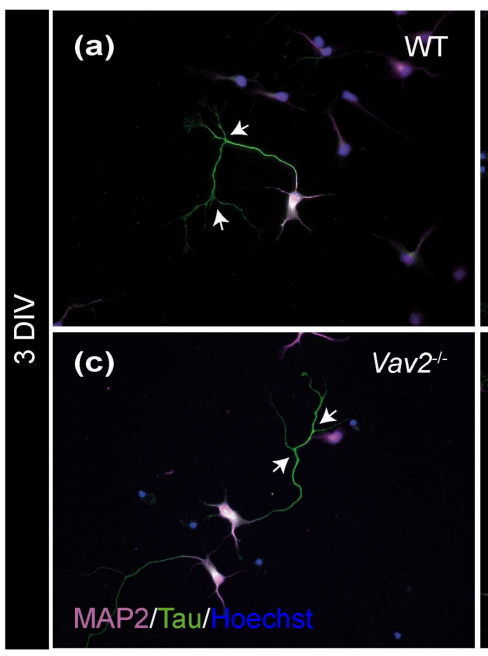

(e)

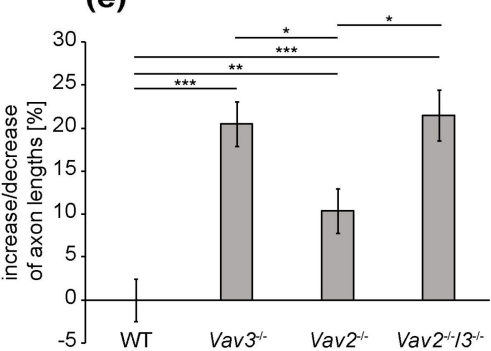

(g)

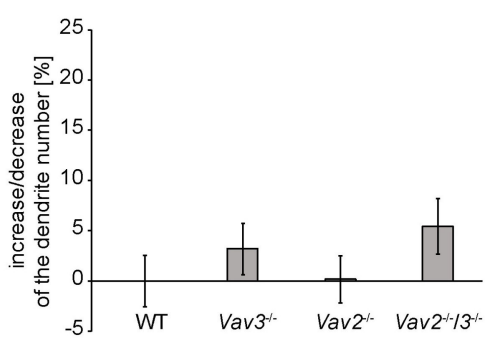

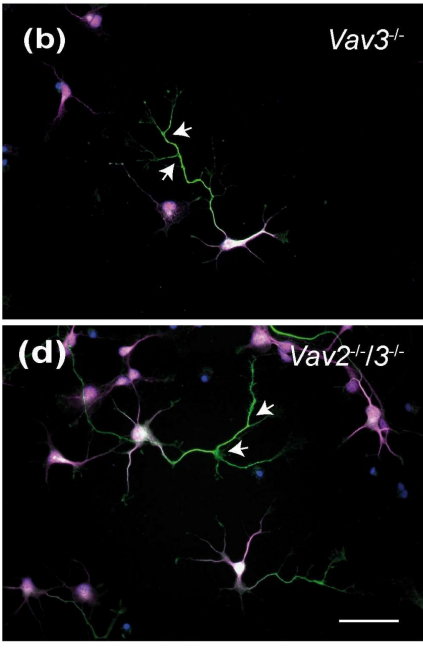

(f)

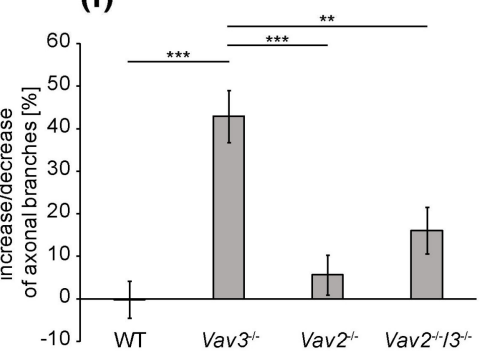

(h)

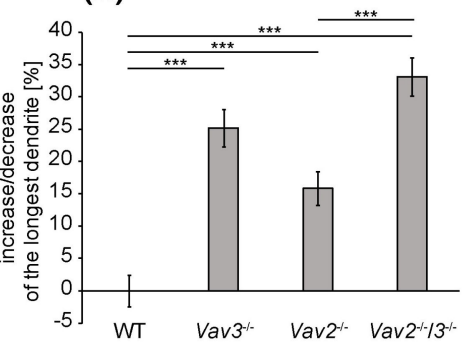

Figure 1. Immunocytochemical staining of MAP2 and Tau in hippocampal neurons after 3 DIV. (a-d) Hippocampal neurons of the different genotypes were cultured for three days and subsequently stained immunocytochemically with antibodies against MAP2 and Tau. While the expression of MAP2 (magenta) is restricted to the somata and dendrites, Tau (green) highly accumulates in the axon. Nuclei were visualized using bisbenzimide (blue) and axonal branches are marked by arrows. $\left(\right.$ e,f) The quantification of axonal parameters revealed that $\mathrm{Vav}^{-/-}$and $\mathrm{Vav}^{-/-} / 3^{-/-}$neurons developed significantly longer and more highly branched axons compared to the wild-type. (g,h) Analysis of the dendrites did not reveal any differences regarding the number but a significant increase of the longest dendrite in the knockout neurons. Statistics: five independent preparations $(N=5)$ were performed and 50-65 neurons ( $n=50-65)$ were randomly chosen per condition, recorded and quantified concerning their axonal lengths and axonal branches, 30 neurons $(n=30)$ were quantified regarding the dendrite number and 45-50 neurons $(n=45-50)$ were used for the analysis of the longest dendrite. Data are shown as mean \pm SEM (Kruskal-Wallis-test, $p \leq 0.05$ ). Scale bar: $50 \mu \mathrm{m}$. 


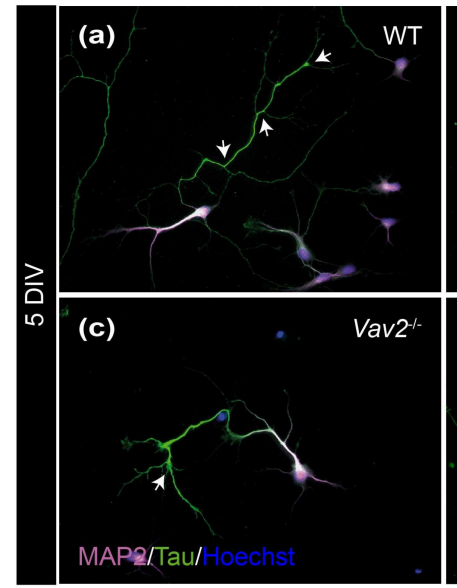

(e)

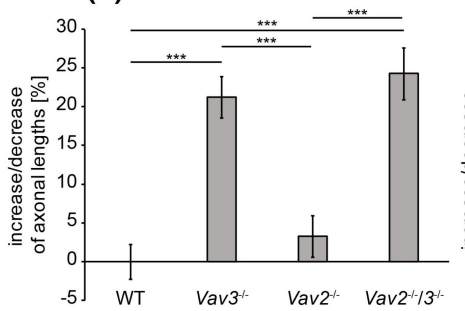

(g)

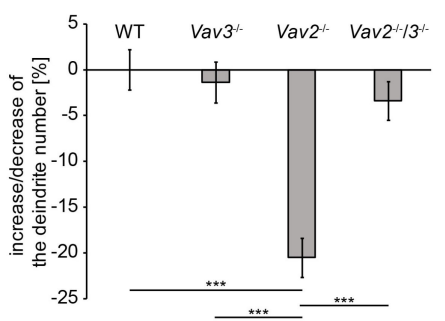

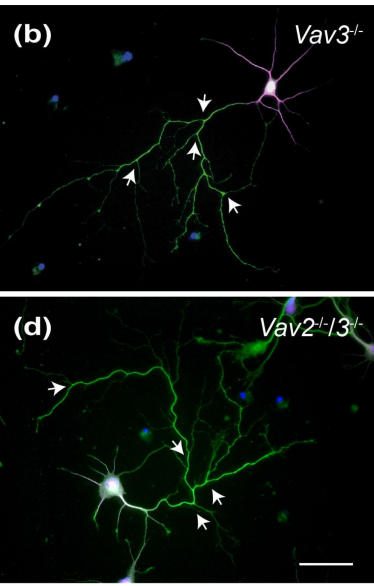

(f)

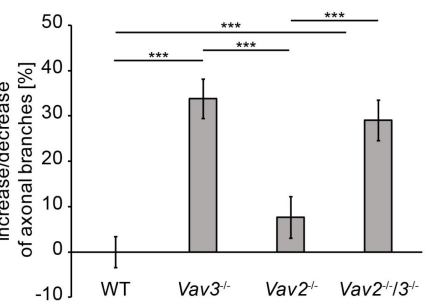

(h)

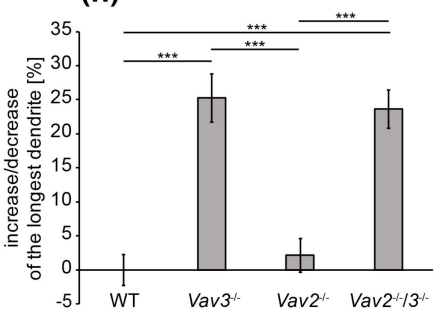

Figure 2. Immunocytochemical staining of MAP2 and Tau in hippocampal neurons after 5 DIV. (a-d) Hippocampal neurons derived from wild-type, Vav2 ${ }^{-/-}, \mathrm{Vav}^{-/-}$and $\mathrm{Vav}^{-{ }^{--}} / 3^{-/-}$mice were cultured for five days and immunostained with antibodies against the dendritic marker MAP2 (magenta) and the axonal marker Tau (green). Nuclei were stained with bisbenzimide (blue) and axonal branches marked with arrows. The representative images illustrate that $\mathrm{Vav} 3^{-1-}$ and $\mathrm{Vav} 2^{-I^{-}} / 3^{-/-}$ neurons (b,d) form longer and more complex axons than wild-type and Vav2 ${ }^{-/-}$neurons (a,c); (e) $\operatorname{Vav}^{-/-}$and $\mathrm{Vav}^{-1-} / 3^{-/-}$neurons developed significantly longer axons than wild-type neurons. (f) The quantification of axon branches revealed a significant increase in $\mathrm{Vav} 3^{-/-}$and $\mathrm{Vav} 2^{-/-} / 3^{-/-}$

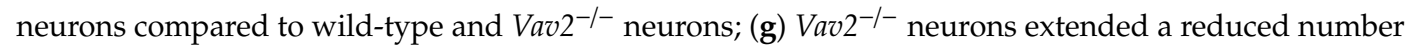
of dendrites in comparison to all other conditions. (h) The average length of the longest dendrite was also significantly higher in $\mathrm{Vav}^{-/-}$and $\mathrm{Vav}^{-/-} / 3^{-/-}$neurons. Statistics: five independent preparations $(N=5)$ were performed and 50-65 neurons $(n=50-65)$ were randomly chosen per condition, recorded and quantified concerning their axonal lengths, 45-60 neurons $(n=45-60)$ were quantified for the axon branch analysis, 30 neurons $(n=30)$ were quantified regarding the dendrite number and $45-50$ neurons $(n=45-50)$ were used for the analysis of the longest dendrite. Data are shown as mean \pm SEM (Kruskal-Wallis-test, $p \leq 0.05$ ). Scale bar: $50 \mu \mathrm{m}$.

To confirm these observations in a more detailed manner, different parameters were quantified and compared with each other (Figure 1e-h). First, the focus was set on the axonal compartment analysing the total number of branches and the average length. The analysis of the axonal length revealed interesting observations (Figure 1e). After 3 DIV, Vav3 ${ }^{-/}$neurons developed the longest axons, which were significantly longer than axons of wild-type neurons $(+20.45 \pm 2.60 \%, p \leq 0.001)$. Similarly, Vav2 $2^{-/-} / 3^{-/-}$neurons also showed elevated axonal lengths $(+21.47 \pm 2.95 \% ; p \leq 0.001)$ compared to 
wild-type. In addition, $\operatorname{Vav}^{-/-}$neurons were also significantly increased in axonal length but to less extent $(+10.36 \pm 2.61 \%, p=0.004)$. Interestingly, $\operatorname{Vav}^{-/-}$neurons developed a significant increase in the total number of branches $(+42.89 \pm 6.08 \%, p \leq 0.001$, Figure 1f) compared to wild-type which was not significantly elevated in $\operatorname{Vav} 2^{-/-} / 3^{-/-}$neurons $(+16.02 \pm 5.50 \%, p=0.320)$.

Next, we analysed dendritic parameters and determined the number of dendrites per neuron and the length of the longest dendrite (Figure $1 \mathrm{~g}-\mathrm{h}$ ). Significant differences in the dendrite numbers could not be observed (Figure 1g). In this respect, neurons of all conditions formed about 5 dendrites per neuron. However, the analysis of the longest dendrite per neuron revealed that $\mathrm{Vav}^{-1-}$ and $\mathrm{Vav}^{-1-} / 3^{-1-}$ neurons formed significantly longer dendrites $\left(\operatorname{Vav}^{-I^{-}}:+25.14 \pm 2.86 \%, p \leq 0.001 ; \operatorname{Vav}^{-/-} / 3^{-/-}:+33.13 \pm 2.98 \%\right.$, $p \leq 0.001$, Figure $1 \mathrm{~h}$ ) than wild-type neurons. Vav2 ${ }^{-/-}$neurons developed slightly longer dendrites $(+15.81 \pm 2.62 \%, p \leq 0.001)$ than wild-type neurons. However, the analysis of the sum of all dendrites per neuron did not reveal significant changes between all groups (see Supplementary Figure S1). The complete set of raw data can be found in the supplementary information (see Supplementary Table S1a).

To determine, whether these differences of fiber length are maintained in later stages of neuronal development, hippocampal neurons of all conditions were analysed after a cultivation period of 5 DIV (Figure 2). It appeared that both, the length and the complexity of axons and dendrites increased after 5 DIV (Figure 2a-d). Especially the axons of $\mathrm{Vav}^{-/-}$and $\mathrm{Vav}^{-{ }^{--}} / 3^{-/-}$neurons attained a high degree of complexity, which was visibly higher compared to the wild-type and Vav2 ${ }^{-/-}$neurons (Figure 2b,d).

The quantitative assessment of axonal and dendritic parameters after 5 DIV underlined these observations and revealed more extensive differences than the analysis after 3 DIV (Figure 2e-h). Thus, axonal lengths of all conditions were determined and compared with each other (Figure 2e). We observed that axons of $\mathrm{Vav}^{-/-}$neurons were significantly longer $(+21.19 \pm 2.66 \%, p \leq 0.001)$ in comparison to the axons of wild-type neurons. Interestingly, analogous results were obtained when quantifying the lengths of $\operatorname{Vav}^{-/-} / 3^{-/-}$neurons $(+24.27 \pm 3.34 \%, p \leq 0.001)$. This was an unexpected result because both Vav2 and Vav3 activate Rho GTPases and, consequently, might have the potential to compensate for each other. This was clearly not the case with regard to this parameter. In agreement with this result, $\operatorname{Vav}^{-/-}$neurons did not display altered axonal lengths compared with wild-type neurons. Next, analysis of the total number of branches revealed that $\operatorname{Vav}^{-/-}$neurons generated a significantly increased number of branches $(+33.88 \pm 4.35 \%, p \leq 0.001$, Figure $2 \mathrm{f})$ compared to wild-type. In addition, $\operatorname{Vav}^{-1-} / 3^{-1-}$ neurons also developed a clear rise of the total number of branches $(+29.02 \pm 4.45 \%, p \leq 0.001)$. However, the deletion of both Vav-genes did not generate any cumulative effects regarding the complexity of axons. Consistent with this conclusion, Vav2 ${ }^{-/-}$neurons developed a comparable total number of axonal branches after 5 DIV as the wild-type. The analysis of the number of individual dendrites revealed no differences between wild-type, $\operatorname{Vav}^{-/-}$and $\operatorname{Vav}^{-/-} / 3^{-/-}$neurons (Figure $2 \mathrm{~g}$ ). However, it turned out that $\mathrm{Vav}^{-/-}$neurons developed a reduced number of dendrites $(-20.48 \pm 2.13 \%, p \leq 0.001)$ compared with wild-type neurons.

The measurement of dendritic lengths resulted in similar ratios as the analysis of the axonal lengths (Figures 1 and $2 \mathrm{~h}$ ). In this respect, the longest dendrites of $\mathrm{Vav}^{-/-}$neurons reached the highest values and were significantly longer than the dendrites of wild-type neurons $(+25.28 \pm 3.57 \%$, $p \leq 0.001)$. The dendrites of $\mathrm{Vav}^{-/-} / 3^{-/-}$neurons reached a similar length than the ones of $\mathrm{Vav}^{-/-}$ neurons, surpassing the wild-type condition $(+23.68 \pm 2.81 \%, p \leq 0.001)$. Here, the measurement of the total sum of all dendrites per neuron did not show significant changes (see Supplementary Figure S1b). The raw data concerning the axo-dendritic parameters after a cultivation time of five days in vitro can be found in the supplementary information (see Supplementary Table S2).

\section{2. $\mathrm{Vav}^{-/-}$and $\mathrm{Vav}^{-{ }^{--}} / 3^{-/-}$Neurons Form a Higher Number of Structural Synapses after 14 but Not after $21 \mathrm{DIV}$}

To answer the question whether the enhanced axonal elongation and branching of $\mathrm{Vav3}^{-1-}$ and Vav2 $2^{-/-} / 3^{-/-}$neurons differentially influenced the formation of synapses, hippocampal neurons of wild-type, $\operatorname{Vav}^{-/-}, \operatorname{Vav}^{-/-}$and $\operatorname{Vav} 2^{-/-} / 3^{-/-}$mice were co-cultured indirectly with cortical astrocytes 
for 14 and 21 days [29,35]. In order to analyse neuron-specific alterations caused by the lack of Vav proteins, exclusively primary cortical wild-type astrocytes were used for the co-cultures. Thereby, identical culture conditions were guaranteed for the different neuronal genotypes. Due to astrocytic factors released into the shared medium, it was possible to cultivate neuronal networks up to 21 days, as previously described [35]. At the end of the cultivation period, the cells were immunostained with antibodies against the presynaptic protein Bassoon and the postsynaptic protein PSD-95 to visualize and quantify structural synapses (Figure 3). The quantification of synaptic puncta after 14 DIV documented that $\mathrm{Vav}^{-/-}$and $\mathrm{Vav} 2^{-/-} / 3^{-/-}$neurons formed significantly more structural synapses than wild-type neurons, as certified by colocalized immunofluorescence signals (Vav3-/- $:+28.96 \pm 0.39 \%$, $p \leq 0.001 ;$ Vav2 $^{-/-} / 3^{-/-}:+29.38 \pm 0.53 \%, p \leq 0.001$, Figure 3e).
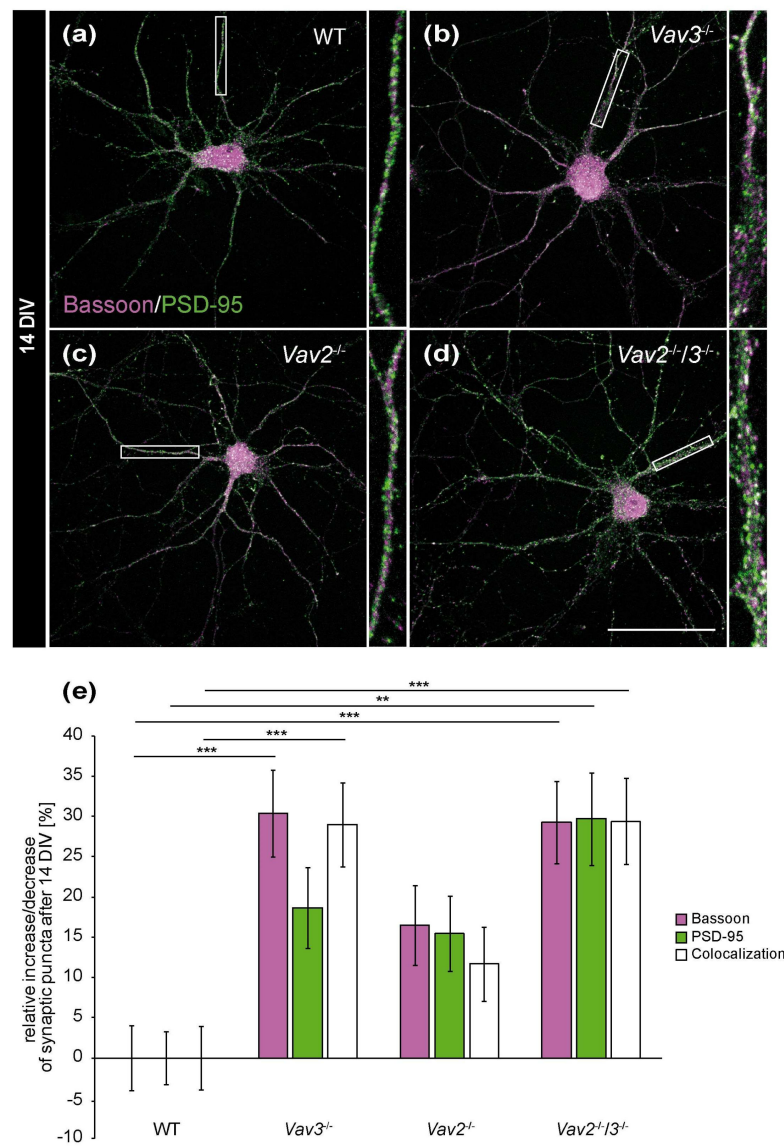

Figure 3. In vitro analysis of the synaptic puncta in hippocampal neurons derived from Vav2 ${ }^{-/}$, Vav $^{-/-}$and Vav2 ${ }^{-/-} / 3^{-/-}$mice after 14 DIV. (a-d) Hippocampal neurons of all conditions were indirectly co-cultured with native cortical astrocytes, fixed after 14 DIV and stained immunocytochemically with antibodies against the presynaptic scaffold protein Bassoon (magenta) and the postsynaptic protein PSD-95 (green). A colocalization of both signals yielded in white puncta which were defined as indicators for structural synapses. (e) The quantification of synaptic puncta revealed a significant raise of presynaptic Bassoon puncta in $\mathrm{Vav}^{-/-}$and $\mathrm{Vav}^{-1-} / 3^{-/-}$neurons. The puncta for PSD-95 were only significantly increased in $\mathrm{Vav}^{-/-} / 3^{-/-}$neurons. Additionally, $\mathrm{Vav}^{-/-}$neurons formed $28.96 \pm 0.39 \%$ and $\mathrm{Vav}^{-/-} / 3^{-/-}$neurons $29.38 \pm 0.53 \%$ more colocalized signals than wild-type neurons after 14 DIV. Statistics: five independent experiments $(N=5)$ have been performed and 20 neurons $(n=20)$ of each condition were randomly recorded and quantified. Data are shown as mean \pm SEM (Kruskal-Wallis-test, $p \leq 0.05$ ) Scale bar: $50 \mu \mathrm{m}$.

Concerning Vav2-/- neurons, only a slight and not significant increase of colocalizations could be observed $(+11.65 \pm 0.46 \%, p=0.285$, Figure $3 c, e)$. The selective quantification of the presynaptic scaffold 
protein Bassoon also revealed interesting differences. Here, a clear increase of Bassoon puncta was observed in the Vav3 $^{-1-}$ and Vav2 ${ }^{-1-} / 3^{-/-}$condition $\left(\right.$Vav3 $^{-1-}:+30.36 \pm 0.54 \%, p \leq 0.001 ;$ Vav $^{-1-} / 3^{-1-}$ : $29.23 \pm 0.51, p \leq 0.001$, Figure 3e). Additionally, an increase of PSD-95 puncta in Vav2 $2^{-/} / 3^{-/-}$neurons was noted $(+29.68 \pm 0.56 \%, p=0.002$, Figure 3e). By comparison, the number of PSD-95 puncta was not significantly augmented in $\mathrm{Vav}^{-1-}$ and $\mathrm{Vav} 2^{-1-}$ neurons.

Interestingly, these differences were not observable any more after 21 DIV (Figure 4e). This holds also true for colocalizations and for Bassoon puncta. Solely a slight reduction of PSD-95-positive puncta was detectable in Vav3 ${ }^{-/-}$neurons $(-14.17 \pm 0.37 \%$, Figure $4 \mathrm{e})$. This decrease was significant regarding the number of PSD-95 puncta of wild-type $(p=0.046), \operatorname{Vav}^{-/-}(p=0.028)$ and $\operatorname{Vav}^{-/-} / 3^{-/-}$ neurons $(p=0.022)$.
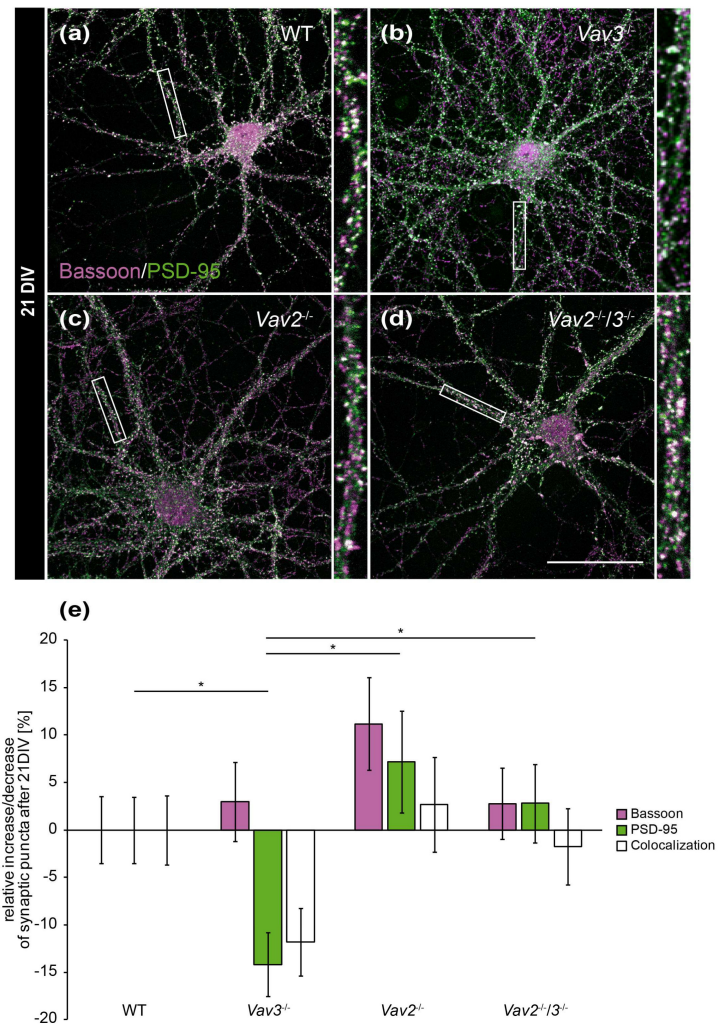

Figure 4. In vitro analysis of the synaptic puncta in hippocampal neurons derived from Vav2 $2^{-/}$, $\mathrm{Vav}^{-/-}$and $\mathrm{Vav}^{-/-} / 3^{-/-}$mice after 21 DIV. (a-d) Neurons derived from embryonic hippocampi of wild-type, $\operatorname{Vav}^{-/-}$, $\mathrm{Vav}^{-/-}$and $\mathrm{Vav}^{-/-} / 3^{-/-}$mice were co-cultured with cortical astrocytes for 21 days and subsequently immunostained with antibodies against the presynaptic protein Bassoon (magenta) and the postsynaptic protein PSD-95 (green). The overlap of immunofluorescence resulted in white puncta, which are classified as indicative of structural synapses. (e) In contrast to the quantification after 14 days in vitro (Figure 3e), no significant changes could be detected between wild-type neurons and any knockout condition after 21 DIV. Vav3 $^{-/-}$neurons exhibited a significant reduction of PSD-95 puncta in comparison to wild-type, $\mathrm{Vav}^{-/-}$and $\mathrm{Vav}^{-1-} / 3^{-/-}$neurons. Statistics: five independent experiments $(N=5)$ have been performed and 20 neurons $(n=20)$ of each condition were randomly recorded and quantified. Data are shown as mean \pm SEM (Kruskal-Wallis-test, $p \leq 0.05)$. Scale bar: $50 \mu \mathrm{m}$. The raw data relating to the structural synapse analysis can be found in the supplementary information (see Supplementary Table S3).

\subsection{Vav3-Deficient Neurons Generated Neuronal Networks that Exhibit a Lower Spontaneous Network Activity and Reduced Synchronization after 21 DIV}

Beyond the immunocytochemical analysis of structural synapses, MEA analysis was applied to examine functional changes of neuronal networks lacking Vav3 (Figure 5). To this end, wild-type 
and $\mathrm{Vav}^{-/-}$neurons derived from the hippocampus were cultured for 14 DIV and 21 DIV on MEAs followed by the measurement of the spontaneous network activity [32].
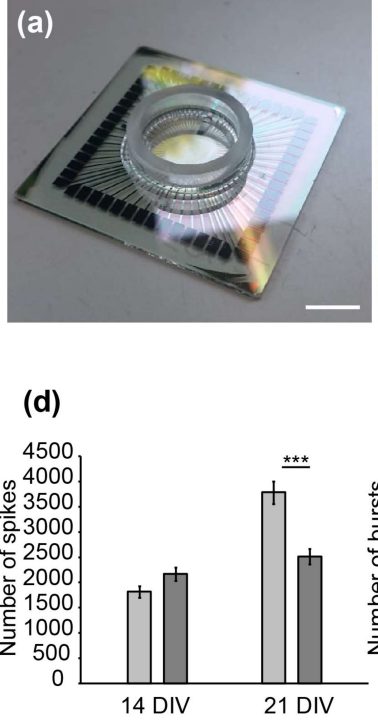

(g)

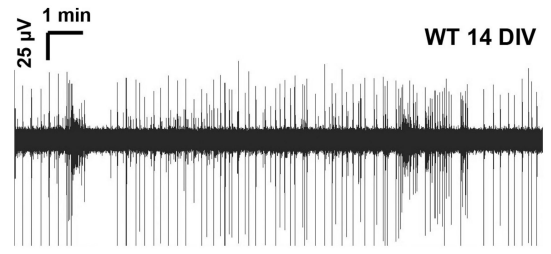

(i)

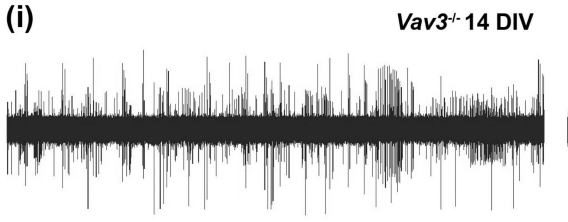

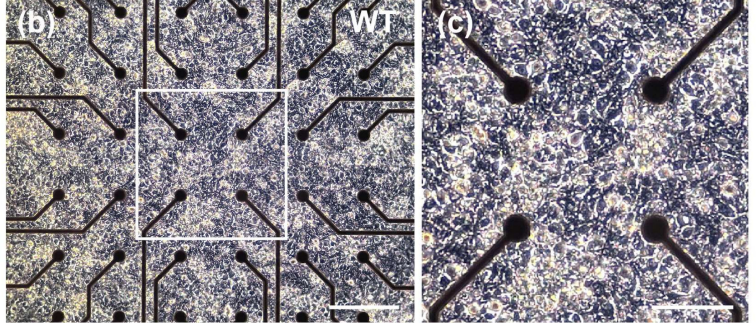

(e)

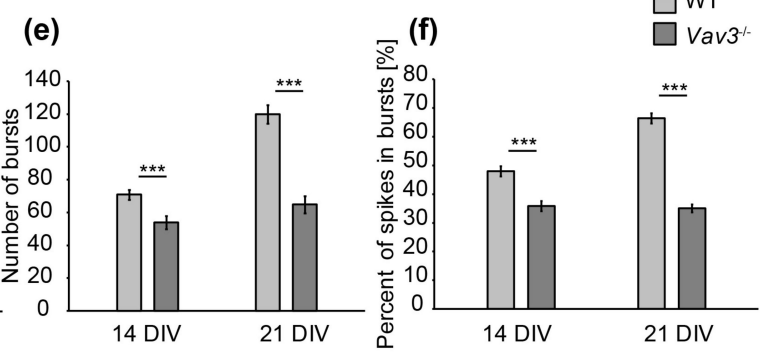

(h)
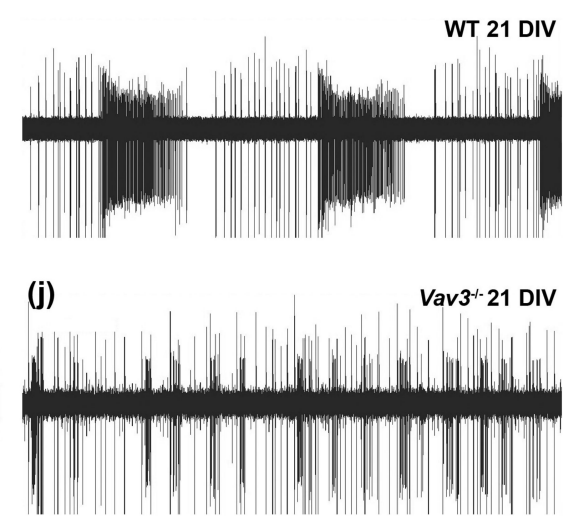

Figure 5. MEA analysis of spontaneous network activity after 14 and 21 DIV. (a) Illustration of a multielectrode array consisting of a centrally located electrode field limited by a glass ring (scale bar: $1000 \mu \mathrm{m})$. (b) Representative image of wild-type hippocampal neurons cultured on a poly-ethylenimine and laminin-1 coated MEA for 14 days in vitro. The electrode field is formed by 60 electrodes consisting of titanium nitride with a diameter of $30 \mu \mathrm{m}$. Action potentials that induce a change of potential in the immediate vicinity to the electrodes can be registered and recorded (scale bar: $100 \mu \mathrm{m}$ ). (c) Close-up of a wild-type cultured neuronal network after 14 days of culture. Neuronal cell soma as well as highly branched neurites can be seen (scale bar: $50 \mu \mathrm{m}$ ). (d) Analysis of single, spontaneously occurring action potentials (spikes) revealed no differences between wild-type and $\mathrm{Vav}^{-/-}$neurons after 14 DIV. However, the number of spikes was significantly reduced in neuronal networks lacking Vav3 in comparison to wild-type neurons after 21 days in vitro. (e) The organized activity of the network was qualified as a burst. Vav3 ${ }^{-/-}$neurons developed a significant decrease of bursts compared with wild-type neurons after 14 and 21 DIV. (f) Furthermore, the percentage of spikes occurring in well-organized bursts was quantified. Wild-type neurons showed a clear increase of spikes occurring in bursts from 14 to 21 DIV. Vav3 ${ }^{-/-}$neurons displayed a highly significant decrease in the proportion of spikes occurring in bursts compare to the wild-type condition. $(g-j)$ Representative measurements over ten minutes of cultured hippocampal neurons derived from wild-type and Vav3 ${ }^{-/}$mice after 14 and 21 days in vitro. Statistics: five independent experiments $(N=5)$ have been performed and the data of 60 electrodes $(n=60)$ was quantified per experiment. Data are shown as mean \pm SEM (Mann-Whitney U-test, $p \leq 0.05)$. Scale bar: $100 \mu \mathrm{m}$. 
After 14 DIV, the number of spontaneously occurring actions potentials, also called spikes, was not significantly altered. Thus, $1817 \pm 116.28$ spikes were observed in wild-type and $2169 \pm 131.13$ spikes in $\operatorname{Vav}^{-/-}$neurons ( $p=0.059$, Figure 5d). After 21 DIV, an average spike number of $3785 \pm 225.26$ could be observed in wild-type neurons. Interestingly, $\mathrm{Vav}^{-1-}$ networks produced an average spike number of $2515 \pm 154.23$ and were therefore significantly less active ( $p \leq 0.001$, Figure $5 \mathrm{~d}$ ). In addition, the coordinated network activity within a short time was analysed by measuring the so-called bursts [36,37]. After a cultivation time of 14 days, the number of bursts was significantly reduced in Vav3-deficient neuronal networks in comparison to wild-type neurons (wild-type: $71 \pm 3.01$; $\operatorname{Vav}^{-/-}: 54 \pm 3.87, p \leq 0.001$, Figure $5 \mathrm{e}$ ). After 21 days in vitro, $120 \pm 5.62$ bursts could be measured in wild-type neurons. The average number of bursts in $\mathrm{Vav}^{-/-}$neurons amounted to $65 \pm 5.22$ at that stage and were significantly reduced ( $p \leq 0.001$, Figure 5e). Last, the percentage of spikes occurring in well-organized bursts was analysed in order to investigate the maturation of neuronal networks in vitro (Figure 5f). After 14 days in vitro, wild-type neurons developed a proportion of $48.01 \pm 1.8 \%$ spikes within bursts. After 21 days in culture, an elevation to a ratio of $66.46 \pm 1.7 \%$ could be observed in wild-type neurons. Interestingly, the percentage of spikes occurring in bursts was significantly reduced in $\mathrm{Vav}^{-/-}$neurons after $14(35.94 \pm 1.76 \%)$ and 21 DIV $(35.11 \pm 1.41 \%)$ in comparison to the wild-type neurons $(p \leq 0.001)$.

In summary, the multielectrode array analysis revealed a significantly downregulated spontaneous network activity of embryonic hippocampal neurons derived from $\mathrm{Vav}^{-1-}$ mice. While an increasing neuronal activity could be observed in wild-type neurons from DIV14 to DIV21, the activity of Vav3-/neurons stagnated after 14 days in vitro. The number of spikes, bursts and the percentual amount of spikes in bursts was significantly ameliorated in knockout cultures.

\section{Discussion}

In the present study, we investigated the role of Vav proteins for the development of neuronal polarity, synapse formation and spontaneous network activity in vitro. We found a significantly increased axonal complexity accompanied with an increased number of presynaptic terminals but reduced levels of activity in neuronal cultures derived from Vav3 lacking embryonic mice. Our observations indicate that in particular Vav3 has important regulatory functions concerning axonal development and synapse formation. In contrast, Vav2 appears to play only a minor role for the development of hippocampal neurons in vitro.

The morphological analysis revealed that hippocampal neurons lacking Vav3, Vav2/3 but not Vav2 form longer axons with a higher level of complexity. Several studies have shown that Vav proteins are potential activators of Rho GTPase family members [7,8]. It has been reported that Vav3 strongly unfolds its nucleotide exchange activity with the targets RhoA and RhoG, whereas Rac1 is activated less efficiently, and Cdc42 not at all [6,8,38]. Interestingly, Vav3 has been found enriched in hippocampal synapses [39] and in hippocampal neuron axons after 5 days in vitro [22].

Vav3-deficient GABAergic neurons of the ventral medulla show deficits in target homing and synapse formation in the brainstem [22]. In the retino-geniculate projection, Vav proteins are required for the induced endocytosis of Eph-ephrin ligand receptor complexes [17]. Neuronal growth cones are specialized and chemo sensitive structures, which respond to extracellular signals with retraction or protrusion of filopodia [40]. Interestingly, Vav proteins activate RhoA, which is implicated in the formation of stress fibres and the collapse of axonal growth cones [14,41-44]. Rac1, another prominent member of the Rho GTPase family, participates in the collapsin and semaphorin induced growth cone collapse [45]. The lack of Vav3 may result in a reduced activity level of RhoA.

Therefore, axonal growth cones of $\mathrm{Vav}^{-/-}$neurons might be less responsive to repulsive extracellular signals. This may represent a possible explanation for the increase of axonal lengths and branching. The extracellular matrix protein tenascin-C exerts repulsive effects on developing axons of neurons [18,46]. Interestingly, a gene trap analysis performed on neural stem cells revealed that Vav3 message is suppressed by tenascin-C [19]. Based on earlier reports and our observations, 
we propose that Vav3 is an important regulator for intracellular rearrangements of the cytoskeleton, thereby playing an important regulatory role for axonal path finding and dendrite elongation in the developing CNS.

Beside the increased axonal lengths, longer dendrites could be observed in $\mathrm{Vav}^{-/-}$and $\mathrm{Vav} 2^{-I^{-}} / 3^{-1-}$ neurons, foremost after 5 DIV. Vav3 seems required for the dendritic branching of Purkinje cells in the cerebellum [20]. The downstream targets of Vav proteins play a crucial role for the development of dendrites. The expression of a constitutively active form of RhoA resulted in an impaired dendritic growth in rat neurons [47]. Conversely, the dominant negative form of RhoA enhanced the development of dendrites in murine hippocampal neurons in vitro [48]. The activation of RhoA is often associated with adverse effects concerning dendrite development. Therefore, RhoA might be responsible for the limitation of dendritic growth. A reduced activity level of RhoA caused by the deletion of Vav2 and Vav3 may therefore entail a reduced inhibition of dendrite development. This could explain the increased dendritic lengths of $\mathrm{Vav}^{-{ }^{--}}$and $\mathrm{Vav}^{-{ }^{--}} \mathrm{3}^{-/-}$neurons observed in our study. Rac1 represents another regulator of dendritic morphology that antagonizes the effects of RhoA. In cortical neurons, the expression of a dominant negative Rac1 caused a reduction of basal dendrites and dendritic spines in cortical neurons $[15,47]$. Conversely, expression of constitutively active Rac1 enacts extensive branching of Purkinje cells [49]. In our studies, we measured promotion of the dendrite lengths of $\mathrm{Vav}^{-/-}$and $\mathrm{Vav}^{-{ }^{--}} \mathrm{3}^{-/-}$neurons. Because Vav3 modulates primarily the activation of RhoA and to a much lesser extent of Rac1 [6], a reduced activation of RhoA consequent to the deletion of Vav3 could be an appealing explanation for the enhanced axonal and dendritic development. To prove this hypothesis, experiments with Rho activators would be interesting and should reveal whether the observed phenotype can be reversed.

The morphological analysis of the dendritic complexity after a longer cultivation time represents an interesting theme. Because the neuronal networks in our assay system develop intricate fibre networks within two weeks, the tracing of dendrites to individual cells is not reliably possible. Therefore, we limited ourselves to brief cultivation periods, which resulted in the simplicity of formed dendrites. For these reasons, potential long-term effects regarding dendrite arborisation could not be addressed in our study.

Our results indicate that $\mathrm{Vav}^{-/-}$and $\mathrm{Vav}^{-/-} / 3^{-/-}$neurons developed a higher number of structural synapses after 14 DIV. We suggest that augmented synaptogenesis arose on the one hand from the enhanced axonal growth and, on the other hand, from stimulated dendrite development. The increased number of axonal branches and lengths may translate into the rise of presynaptic terminals and eventually produce a higher number of co-localized puncta. In accordance with this assumption, more presynaptic Bassoon puncta were visible after 14 DIV. Along these lines, the expansion of dendrites probably enhances the target areas for the axonal growth cones. Interestingly, the Rho GTPases RhoA and Rac1 regulate the formation and maintenance of dendritic spines in hippocampal pyramidal neurons and in Purkinje cells [47,49-51]. For example, the inhibition of RhoA using the enzyme C3-transferase caused an abnormal increase of dendritic spines in hippocampal pyramidal neurons [50]. In contrast, a dominant negative form of Rac1 did not enact noteworthy differences in spine morphology [50]. As the Vav proteins impinge on both RhoA and Rac1, it is difficult to judge which of the potential pathways is implicated in synaptogenesis. After 21 DIV, all cultures attained a comparable number of synaptic puncta. This indicates that wild-type and Vav2 $2^{-/}$neurons eventually reached the same level of complexity as $\mathrm{Vav}^{-/-}$and Vav2 $2^{-1-} / 3^{-/-}$neurons, however, on a protracted time scale. These observations highlight Vav3 as an important regulator of the initial neuronal development in vitro. Interestingly, cerebellar development is altered in $\mathrm{Vav}^{-/-}$mice. Behavioural experiments revealed deficits concerning motor coordination and gaiting during the early postnatal period of $\mathrm{Vav}^{-/-}$mice that ameliorated in older animals [20,52].

In our studies using MEAs, we could measure a decrease of spontaneous and of organized network activity in Vav3 deficient neurons. Little is known about the roles of Vav proteins and their downstream targets, RhoA and Rac1, concerning the activity of neuronal networks. Interestingly, 
some studies indicate an important role of Rho GTPases for neurosecretion [12]. Recent findings revealed that Rho GTPases are activated during synaptic transmission in the CA1 region of rat hippocampus [53]. Furthermore, the activation of RhoA and Rac1 by CNF1 leads to enhanced neurotransmission, synaptic plasticity and improved learning and memory in mice [54]. Conversely, the RhoA inhibitor C3 transferase decreased the presynaptic release of acetylcholine in C. elegans [55]. The reduced spontaneous network activity of $\mathrm{Vav3}^{-/-}$neurons on MEAs could hence be explained by an impaired release of neurotransmitter. Although we observed an increased number of structural synapses after $14 \mathrm{DIV}$, the number of spontaneously occurring action potentials was reduced at this point in time. An increased number of structural synapses is not necessarily accompanied by an increase in electrophysiological activity and might be explained by the presence of so-called silent synapses. Silent synapses have been described in the developing hippocampus and are characterized by the lack of AMPA-receptors in the postsynaptic compartment, rendering them unable to mediate synaptic transmission under physiological conditions [56,57]. This type of synapses is supposedly detectable in immature synapses and might indicate an impairment of synaptic maturation in neurons lacking Vav3. Interestingly, a compromised glutamatergic synapse maturation and AMPA-receptor stability was observed when the Rho-GTPase-activating protein oligophrenin-1 was defective or decreased [58]. Several reports emphasize further links between mental retardation syndromes and alterations in small GTPases or GTPase regulating proteins $[59,60]$.

While we observed differences in axonal and dendritic morphology as well as in synapse formation and network activity of $\mathrm{Vav}^{-/-}$and $\mathrm{Vav}^{-/-} / 3^{-/-}$neurons, $\mathrm{Vav}^{-/-}$neurons exhibited only slight or no visible modifications. Furthermore, the $\operatorname{Vav} 2^{-1-} / 3^{-1-}$ neurons did not display evidence of cumulative effects and resembled in their morphology the $\mathrm{Vav3}^{-/-}$neurons. This is indicative of a negligible role of Vav2 with regard to the development of axons and dendrites. On the other hand, this finding underlines that the genetic ablation of a Vav gene by itself is not sufficient to impact the cell biology of neurons. In this sense, the $\mathrm{Vav} 2^{-/-}$can be considered a supplemental independent control for the $\mathrm{Vav}^{-/-}$phenotype, beyond the wild-type.

The sole phenomenon of significance was a reduced number of dendrites after 5 days in vitro. This phenotype of $\mathrm{Vav}^{-/-}$neurons vanished at later time points of cultivation. Analogous observations with respect to Vav2 were reported concerning the development of the cerebellum [20]. Alternatively, Vav2 and Vav3 might be expressed to different degrees in the CNS. In fact, in situ hybridizations revealed high expression levels of Vav3 message in particular in the hippocampus and the cerebellum but a generally lower expression of Vav2 (Allen Mouse Brain Atlas, http://www.brain-map.org) [25,26]. Therefore, it is conceivable that $\operatorname{Vav} 3$ compensates the knockout of Vav2 whereas the opposite option is improbable. Of note, the Vav protein family forms a small subgroup of the "transforming oncogene of diffuse B-cell lymphoma" (DBL) family of GEFs that comprises more than 60 genes in the human [61]. Therefore, not only GEFs of the Vav protein family might compensate the knockout of Vav 2 but also GEFs of other protein families. The great number of GEFs poses a serious challenge for the identification of compensatory mechanisms and should be the aim of follow-up projects.

According to current views, the expression level of small GTPases of the RhoA-family is not rate limiting for their respective activity. Rather, the activation state depends on the controlling GEFs, GAPs and GDIs in the cellular context [62]. In support of this notion it has been reported that the levels of activated Rac1 are reduced in immune cells of the Vav2 knockout mutant, while its protein levels are unchanged. We therefore conclude that the differences we observe in our study are not a consequence of varying levels of effectors $[63,64]$.

In summary, our data revealed that primarily Vav3, but not Vav2, is involved in axon elongation and branching, in dendrite development and, finally, in synapse formation of hippocampal neurons in vitro. Future studies with transgenic knockout mice may focus on the behaviour of axonal growth cones in distinct extracellular microenvironments. In that regard, it will be of interest to examine whether Vav proteins regulate or tune the growth cone response to promoting or repulsive stimuli. In this context, the identification of GTPases controlled downstream of Vav represents an important objective which 
will require the development of tools to monitor GTPase activities in small cell populations. In the light of the current knowledge, members of the RhoA subfamily of GTPases represent attractive candidates. For example, current studies focus on the therapeutic inhibition of RhoA, which is correlated with an enhanced neuronal survival and axon regeneration after lesion [65-69]. Progress in this research field may help to develop new therapies and strategies to treat CNS lesions.

\section{Materials and Methods}

\subsection{Animals}

Wild-type SV129, Vav2, Vav3 and Vav2/3 knockout mice were used in accordance with the Society for Neuroscience and European Union guidelines, European Council Directive of September 22, 2010 (2010/63/EU), for care of laboratory animals and approved by the animal care committee of North Rhine-Westphalia, Germany, based at the LANUV (Landesamt für Umweltschutz, Naturschutz und Verbraucherschutz, Nordrhein-Westphalen, D-45659 Recklinghausen, Germany). The animal wellfare commissioner of Ruhr-University supervised the study. Animals of both sexes were used for the experiments and kept under standardized conditions with regulated humidity and $24 \mathrm{~h}$ dark/light circle. The supply with food and water was ensured ad libitum. Wild-type SV129 and Vav3 ${ }^{-1-}$ mice originate from the mouse breed of the Department for Cell Morphology and Molecular Neurobiology of the Ruhr-University Bochum [70]. The $\mathrm{Vav} 2^{-/-} / 3^{-/-}$double knockout mouse line [71] was used to outbreed Vav2 ${ }^{-/-}$mice [72] and both lines were kept in the animal facility of the faculty of Biology and Biotechnology of Ruhr University.

\subsection{Immunological Reagents}

The following rabbit polyclonal antibodies were used: anti-bassoon (1:1000; RRID:AB_887697; Synaptic Systems), anti-MAP2 (1:300; RRID:AB_1840999; Sigma-Aldrich (by Merck KGaA), Darmstadt, Germany. Additionally, the monoclonal mouse antibody against postsynaptic-density protein 95 (PSD-95, 1:500; RRID:AB_94278; Merck Millipore, Darmstadt, Germany) and the monoclonal chicken antibody against Tau (1:300; RRID:AB_1310734; Abcam) were used. All secondary antibodies were obtained from Dianova. These were labelled with Cy3 (1:500) or AF488 (1:250) and showed specificity for the primary mouse, rabbit and chicken antibodies. The detection of cellular nuclei occurred with bisbenzimide (Hoechst 33258, 1:100.000; Sigma-Aldrich).

\subsection{Dissection and Cell Culture}

To analyse the synaptogenesis, hippocampal neurons and cortical astrocytes were co-cultured indirectly $[29,35,73]$. For the cultivation of cortical astrocytes, postnatal mice (P1-P3, SV129) were decapitated. Afterwards, the cortices were extracted and freed from the meninges. The cortices were incubated in a digestion solution containing $30 \mathrm{U}$ Papain (Worthington), $40 \mu \mathrm{g} / \mathrm{mL} \mu \mathrm{L}$ DNase I (Worthington) and $0.24 \mathrm{mg} / \mathrm{mL}$ L-cysteine (Sigma-Aldrich) in DMEM (Gibco) for $1 \mathrm{~h}$ at $37^{\circ} \mathrm{C}$. Then the digestion solution was removed and replaced by astrocyte medium composed of DMEM (Gibco) with $10 \% v / v$ horse serum (Gibco) and $0.1 \% v / v$ gentamicin (Sigma-Aldrich). After stopping the process of digestion, the tissue was triturated mechanically and centrifuged for $5 \mathrm{~min}$ at $1000 \mathrm{rpm}$. The supernatant was discarded, and the cell pellet was resuspended in $1 \mathrm{~mL}$ fresh astrocyte medium. After this, $1 \mathrm{~mL}$ single-cell suspension was added to $9 \mathrm{~mL}$ of astrocyte medium in a T-75 culture flask (Sarstedt) pre-coated with $10 \mu \mathrm{g} / \mathrm{mL}$ poly-D-lysine (Sigma-Aldrich). For equal density, six cortices were used per flask. The astrocytes were cultured at $37^{\circ} \mathrm{C}$ and $6 \% v / v \mathrm{CO}_{2}$, with a total medium exchange every second day.

After a cultivation time of 7-8 days, the astrocytes formed a monolayer but still contained unwanted microglia and oligodendrocyte precursor cells. To obtain a pure astrocyte culture, T-75 flasks were initially shaken for $1 \mathrm{~h}$ on an orbital shaker (New Brunswick Scientific (by Fisher Scientific $\mathrm{GmbH}$, Schwerte, Germany) at $250 \mathrm{rpm}$ and $37^{\circ} \mathrm{C}$. Then the complete medium was exchanged, 
and the flasks were shaken overnight. Subsequently, the medium was exchanged and $20 \mu \mathrm{M}$ cytosine-1- $\beta$-D-arabinofuranoside (Ara-C, Sigma Aldrich) was added for 48-72 h.

For the co-cultivation with hippocampal neurons, pure astrocytes were plated in cell culture inserts (pore size: $0.4 \mu \mathrm{m}$; BD Falcon). Therefore, the astrocytes were incubated with trypsin/EDTA $(0.1 \% w / v$ trypsin with EDTA in MEM, both from Gibco) for 5-10 min at $37^{\circ} \mathrm{C}$ with $6 \% v / v \mathrm{CO}_{2}$. Subsequently, 25,000 astrocytes were plated in the inserts pre-coated with $10 \mu \mathrm{g} / \mathrm{mL}$ poly-D-lysine. The main purpose to use wild-type cortical astrocytes in our co-culture system was the prolongation of the cultivation time of hippocampal neurons in completely defined medium, as previously described $[29,35]$. As we used identical culture conditions for wild-type and the diverse mutant neurons, differences in neuronal biology emerging in our approach should exclusively be caused by the different genotypes of the neurons, that is, the deletion of the corresponding Vav genes.

To cultivate hippocampal neurons, pregnant mice were euthanized by cervical dislocation and embryonic mice (E 15.5) were removed. The hippocampi were dissected carefully and relieved from meninges and surrounding tissue. Then, the hippocampi were collected in dissection medium consisting of HBSS (Gibco), 0.6\% v/v glucose (J.T. Baker) and 10 mM HEPES (Gibco). Afterwards, the hippocampal tissue was digested using $30 \mathrm{U}$ Papain (Worthington) in MEM (Gibco) with $40 \mu \mathrm{g} / \mathrm{mL} \mu \mathrm{L}$ DNase and $0.24 \mathrm{mg} / \mathrm{mL}$ L-cysteine for $15 \mathrm{~min}$ at $37^{\circ} \mathrm{C}$. The digestion solution was replaced by hippocampus medium containing MEM (Gibco), 2\% v/v B27 (Gibco), 0.1\% v/v ovalbumin (Sigma-Aldrich), $10 \mathrm{mM}$ sodium pyruvate (Gibco) and $0.1 \%$ v/v gentamicin (Sigma-Aldrich). After three washing steps, the hippocampi were triturated mechanically to a single cell suspension. To analyse the neuronal morphology, 30,000 cells of each condition were plated out on glass coverslips (Thermo Scientific) pre-coated with $15 \mu \mathrm{g} / \mathrm{mL}$ poly-L-ornithin (Sigma-Aldrich) in 4-well plates (Nunc).

For the indirect co-cultivation with astrocytes and the analysis of synapse formation, it was necessary to cultivate a higher number of neurons. Therefore, 35,000 cells were plated out on glass coverslips, also pre-coated with $15 \mu \mathrm{g} / \mathrm{mL}$ poly-L-ornithine (Sigma-Aldrich), in 24-well plates (BD Falcon). After $1 \mathrm{~h}$, the cell culture inserts (Corning GmbH, Kaiserslautern, Germany) with astrocytes were added to the neurons. In a previous step, the astrocyte medium was replaced by hippocampus medium. The indirect co-cultures were composed of neurons from SV129, $\operatorname{Vav}^{-1-}, \mathrm{Vav}^{-/-}$and Vav $2^{-/-} / 3^{-/-}$mice and astrocytes from SV129 mice. The cells were cultured under constant conditions at $37^{\circ} \mathrm{C}$ and $6 \% \mathrm{CO}_{2}$ in a humidified incubator.

The number of neurons plated in our culture system is not sufficient to apply commercially available assay kits to measure the activation of RhoA/Rac1/Cdc42 directly. Therefore, we compared different genotypes, namely wild-type, and three mutant $\left(\operatorname{Vav}^{-/-}, \mathrm{Vav}^{-/-}\right.$and $\left.\mathrm{Vav}^{-{ }^{--}} \mathrm{3}^{-{ }^{--}}\right)$mouse lines under identical culture conditions. Any difference measured in our assay system should reflect functional differences for neuronal differentiation of the genes under study.

\subsection{Immunocytochemistry}

In order to analyse the axonal and dendritic parameters, hippocampal neurons were fixed after 3 and 5 DIV. Therefore, the medium was carefully removed and replaced by pre-warmed $4 \% w / v$ paraformaldehyde (Sigma-Aldrich) for $10 \mathrm{~min}$. After three washing steps with PBS, the cells were incubated with the primary antibody solution over night at $4{ }^{\circ} \mathrm{C}$ in a humid chamber. Previously, primary antibodies were diluted in PBT1 (PBS with $0.1 \% v / v$ Triton X-100; Sigma-Aldrich and $1 \% w / v$ BSA; AppliChem). Next, the primary antibody solution was aspirated, and the cells were washed three times with PBS/A (PBS containing 0.1\% w/v BSA; AppliChem). Secondary antibodies were diluted in $\mathrm{PBS} / \mathrm{A}$ and incubated for $1 \mathrm{~h}$ at room temperature. After that, cells were rinsed three times with PBS and once with Milli-Q water (Merck Millipore, Darmstadt, Germany). In a final step the cells were covered on microscope slides (Thermo Fisher Scientific, Bleiswijk, The Netherlands) using Immumount (Thermo Scientific) and stored at $4{ }^{\circ} \mathrm{C}$ until use.

To examine changes in structural synapses, neurons were co-cultured indirectly with astrocytes and fixed with $4 \% w / v$ paraformaldehyde (Sigma-Aldrich) after 14 and 21 days in culture. After fixation, 
neurons were rinsed three times with PBS and incubated for 20 min with $25 \mathrm{mM}$ glycine (J.T.Baker). In a following step, the glycine solution was replaced by a blocking buffer consisting of PBS with $10 \%$ $v / v$ horse serum (Gibco) and 0.1\% v/v Triton X-100 (Sigma-Aldrich) for $1 \mathrm{~h}$. Primary antibodies were diluted in blocking buffer and incubated for $1 \mathrm{~h}$ in a humid chamber. After washing with blocking buffer twice, the secondary antibodies were also diluted in blocking buffer followed by incubation for $1 \mathrm{~h}$ in a dark humid chamber. Finally, the cells were rinsed twice with blocking buffer, once with PBS, once with Milli-Q water (Millipore) and finally covered on microscope slides (Thermo Scientific) with Immumount (Thermo Scientific). The samples were stored at $4{ }^{\circ} \mathrm{C}$ until images were taken at the microscope.

\subsection{Electrophysiology}

The spontaneous network activity of cultured wild-type and $V a v 3^{-/-}$neurons was measured with multielectrode arrays (MEA, Multichannel Systems). In a first step the electrode fields were coated with $0.05 \% v / v$ poly-ethylenimine (PEI, Sigma-Aldrich) for $1 \mathrm{~h}$ at room temperature. After carefully removing the PEI, the MEAs were washed three times with Milli-Q water (Millipore) and air dried under ultraviolet light. Then, the electrode fields were coated with $5 \mu \mathrm{g} / \mathrm{mL} w / v$ laminin (Thermo Scientific) for $20 \mathrm{~min}$ at $37^{\circ} \mathrm{C}$. Afterwards, the laminin solution was removed and replaced by the neuronal cell suspension. A total number of 30,000 neurons in $30 \mu \mathrm{L}$ hippocampus medium $\left(1 \times 10^{6}\right.$ cells per $\left.\mathrm{ml}\right)$ was plated out per electrode field. The cell density on electrode fields was visually controlled under the microscope and replenished by addition of another $30 \mu \mathrm{L}$ of cell suspension, if necessary.

After an incubation time of $10 \mathrm{~min}$, the MEAs were flooded with $1 \mathrm{~mL}$ hippocampus medium and stored for $1 \mathrm{~h}$ at $37^{\circ} \mathrm{C}$ and $6 \% v / v \mathrm{CO}_{2}$ to settle and adhere to the substrate. The cell culture inserts (BD Falcon) with astrocytes were added using specially constructed racks after replacing the astrocyte medium with hippocampus medium. Then the co-cultures were transferred into plastic boxes with special covers consisting of fluorinated ethylene-propylene [32]. The cultivation succeeded at $37^{\circ} \mathrm{C}$ and $6 \% v / v \mathrm{CO}_{2}$ in a humidified incubator.

The measurement of the spontaneous network activity was performed after 14 and 21 DIV. First, the MEAs were positioned on a $35^{\circ} \mathrm{C}$ pre-heated pre-amplifier and left for $10 \mathrm{~min}$ to avoid an unwanted activity, caused by the transport. Then, the spontaneous network activity was recorded for $10 \mathrm{~min}$ using a sample rate of $20 \mathrm{kHz}$, considering all 60 electrodes. The data was recorded with the program MCRack (Version 3.9.0, Multichannel Systems, Reutlingen, Germany). A high-pass filter with an adjusted frequency of $200 \mathrm{~Hz}$ eliminated field potentials from the raw data. In addition, a spike detector was used, which recorded single spontaneous amplitudes 4.5-fold higher than the standard deviation. In order to detect bursts, the following settings were adjusted: maximal interval initiating a burst, $10 \mathrm{~ms}$; maximal interval terminating a burst, $100 \mathrm{~ms}$; maximal interval between two bursts, $210 \mathrm{~ms}$; minimal duration of a burst, $50 \mathrm{~ms}$; minimal number of spikes per burst, 5 .

To remove cells, the medium was aspirated, replaced by $1 \% w / v$ tergazyme (Alconox) and incubated overnight at room temperature. After aspirating and discarding, the degraded cells the MEAs were washed three times with Milli-Q water (Millipore) and stored at $4{ }^{\circ} \mathrm{C}$ until next usage.

\subsection{Microscopy}

Images of MAP2/Tau-immunostained neurons were recorded using a fluorescence microscope (AxioPlan 2, Zeiss, Jena, Germany) with an affiliated digital camera (AxioCam MRm, Zeiss). The associated AxioVision 4.5 software (Zeiss) was used for the documentation. Recordings of immunostained synaptic proteins were taken with the confocal laser scanning-microscope LSM 510 Meta (Zeiss). A z-stack width of $0.25 \mu \mathrm{m}$ was adjusted for the scanning procedure. The number of z-stacks varied between 5 and 7 depending on the size of the individual neuron. Afterward, every single image was assembled to an overlay. The settings for the gain and threshold were kept constant for all experimental repetitions. 


\subsection{Quantification}

To compare the morphology of wild-type, $\mathrm{Vav3}^{-/-}, \mathrm{Vav}^{-{ }^{--}}$, and $\mathrm{Vav}^{-\mathrm{I}^{-}} / \mathrm{3}^{-/-}$neurons, different axonal and dendritic properties were analysed. The axonal parameters included length and total number of branches. In addition, the number of dendrites per neuron and the length of the longest dendrite were measured. The program ImageJ was used to examine 50-65 neurons per experimental replicate. All data are represented as the increase/decrease relative to the mean of the wild-type condition. Therefore, the following formula was used: $\frac{(\text { value-WT mean })}{\text { WT mean }} \times 100$.

Quantification of the synaptic puncta was carried out with the Plug-in "puncta analyser" for ImageJ from Barry Wark (licensed under http://www.gnu.org/copyleft). In order to measure the number of presynaptic Bassoon and postsynaptic PSD-95 puncta following settings had been adjusted: ball radius, 50 pixels; size (pixel2), 2-infinity; circularity, 0.00-1.00 [74]. Co-localizations of the fluorescent signals were considered as indications for structural synapses [35]. For the statistics, 20 immunostained neurons were evaluated per experimental procedure. Finally, the numbers of synaptic puncta of wild-type, $\operatorname{Vav}^{-/-}, \mathrm{Vav}^{-/-}$and $\mathrm{Vav} 2^{-/-} / 3^{-/-}$neurons were compared with each other and presented as the relative increase/decrease as mentioned before. The experiments with MEAs were performed with wild-type and $\mathrm{Vav}^{-/-}$neurons. To compare the network activity of cultured hippocampal neurons, data of all 60 electrodes were considered [32]. The number of spikes and bursts were quantified for all conditions.

\subsection{Statistics}

For the statistical analysis, the program IBM SPSS Statistic was used. First the Kolmogorov-Smirnov test was applied to identify the distribution of all data sets. Data sets concerning the axonal and dendritic parameters as well as the immunocytochemical synaptic puncta analysis were not normally distributed. For this reason, the Kruskal-Wallis test was chosen to analyse the level of significance. The values of the MEA analysis were also not normally distributed. Here, the Mann-Whitney $U$-test was applied to examine the significance. The detailed number of independent experiments and the corresponding level of significance are indicated in the figure legends. The significance level was set at $p \leq 0.05$. Data are given with the mean value and the standard error of the mean $( \pm$ SEM).

Supplementary Materials: Supplementary materials can be found at http://www.mdpi.com/1422-0067/21/3/856/s1.

Author Contributions: Conceptualization, D.W. and C.W.; Data curation, D.W.; Funding acquisition, A.F.; Investigation, C.W.; Methodology, D.W., C.W. and A.F.; Project administration, A.F.; Resources, K.T., K.-D.F. and A.F.; Supervision, D.W. and A.F.; Validation, D.W.; Visualization, D.W.; Writing-Original draft, D.W.; Writing-Review and editing, D.W. and A.F. All authors have read and agreed to the published version of the manuscript.

Funding: This research was funded by the German Research Foundation (Deutsche Forschungsgemeinschaft DFG: SFB 642 TPA24; FA 159/22-1), the International Graduate School of Neuroscience (IGSN) and the Research Department of Neuroscience (RDN) of the Ruhr University. K.D.F. was supported by the ABINEP graduate school funded by the Ministry for Economics, Science, and Digitization of the State Saxony-Anhalt, and by the European Fonds for Social and Regional Development (EFRE, ESF).

Conflicts of Interest: The authors declare no conflict of interest. The funders had no role in the design of the study; in the collection, analyses, or interpretation of data; in the writing of the manuscript, or in the decision to publish the results.

\section{Abbreviations}

$\begin{array}{ll}\text { Ara-C } & \text { cytosine-1- } \beta \text {-D-arabinofuranoside } \\ \text { Cdc42 } & \text { cell division control protein } 42 \\ \text { CNF-1 } & \text { Escherichia coli necrotizing factor } 1 \\ \text { CNS } & \text { central nervous system } \\ \text { DIV } & \text { days in vitro }\end{array}$




$\begin{array}{ll}\text { DNase } & \text { desoxyribonuclease } \\ \text { E } & \text { embryonic } \\ \text { GABA } & \gamma \text {-aminobutric acid } \\ \text { GDP } & \text { guanosine diphosphate } \\ \text { GEF } & \text { guanine nucleotide exchange factor } \\ \text { GTP } & \text { guanosine triphosphate } \\ \text { KO } & \text { knockout } \\ \text { LSM } & \text { laser scanning microscope } \\ \text { MAP2 } & \text { microtubule-associated protein 2 } \\ \text { MEA } & \text { multielectrode array } \\ \text { mRNA } & \text { messenger ribonucleic acid } \\ \text { PSD-95 } & \text { postsynaptic density protein 95 } \\ \text { Rac1 } & \text { Ras related C3 botulinum toxin substrate 1 } \\ \text { RhoA } & \text { Ras homolog gene family member A } \\ \text { RhoG } & \text { Ras homolog gene family member G } \\ \text { SEM } & \text { standard error of the mean } \\ \text { WT } & \text { wild-type }\end{array}$

\section{References}

1. Rodriguez-Fdez, S.; Bustelo, X.R. The Vav GEF Family: An Evolutionary and Functional Perspective. Cells 2019, 8, 465. [CrossRef] [PubMed]

2. Katzav, S. Vav1: A hematopoietic signal transduction molecule involved in human malignancies. Int. J. Biochem. Cell Biol. 2009, 41, 1245-1248. [CrossRef] [PubMed]

3. Katzav, S.; Martin-Zanca, D.; Barbacid, M. vav, a novel human oncogene derived from a locus ubiquitously expressed in hematopoietic cells. EMBO J. 1989, 8, 2283-2290. [CrossRef] [PubMed]

4. Turner, M.; Billadeau, D.D. VAV proteins as signal integrators for multi-subunit immune-recognition receptors. Nat. Rev. Immunol. 2002, 2, 476-486. [CrossRef] [PubMed]

5. Schuebel, K.E.; Bustelo, X.R.; Nielsen, D.A.; Song, B.J.; Barbacid, M.; Goldman, D.; Lee, I.J. Isolation and characterization of murine vav2, a member of the vav family of proto-oncogenes. Oncogene 1996, 13, 363-371. [PubMed]

6. Movilla, N.; Bustelo, X.R. Biological and regulatory properties of Vav-3, a new member of the Vav family of oncoproteins. Mol. Cell. Biol. 1999, 19, 7870-7885. [CrossRef] [PubMed]

7. Crespo, P.; Schuebel, K.E.; Ostrom, A.A.; Gutkind, J.S.; Bustelo, X.R. Phosphotyrosine-dependent activation of Rac-1 GDP/GTP exchange by the vav proto-oncogene product. Nature 1997, 385, 169-172. [CrossRef]

8. Movilla, N.; Dosil, M.; Zheng, Y.; Bustelo, X.R. How Vav proteins discriminate the GTPases Rac1 and RhoA from Cdc42. Oncogene 2001, 20, 8057-8065. [CrossRef]

9. Aoki, K.; Nakamura, T.; Fujikawa, K.; Matsuda, M. Local phosphatidylinositol 3,4,5-trisphosphate accumulation recruits Vav2 and Vav3 to activate Rac1/Cdc42 and initiate neurite outgrowth in nerve growth factor-stimulated PC12 cells. Mol. Biol. Cell 2005, 16, 2207-2217. [CrossRef]

10. Ulc, A.; Gottschling, C.; Schäfer, I.; Wegrzyn, D.; van Leeuwen, S.; Luft, V.; Reinhard, J.; Faissner, A. Involvement of the guanine nucleotide exchange factor Vav3 in central nervous system development and plasticity. Biol. Chem. 2017, 398, 663-675. [CrossRef]

11. Jaffe, A.B.; Hall, A. Rho GTPases: Biochemistry and biology. Annu. Rev. Cell Dev. Biol. 2005, 21, $247-269$. [CrossRef] [PubMed]

12. Momboisse, F.; Houy, S.; Ory, S.; Calco, V.; Bader, M.F.; Gasman, S. How important are Rho GTPases in neurosecretion? J. Neurochem. 2011, 117, 623-631. [CrossRef] [PubMed]

13. Stankiewicz, T.R.; Linseman, D.A. Rho family GTPases: Key players in neuronal development, neuronal survival, and neurodegeneration. Front. Cell Neurosci. 2014, 8, 314. [CrossRef] [PubMed]

14. Wu, K.Y.; Hengst, U.; Cox, L.J.; Macosko, E.Z.; Jeromin, A.; Urquhart, E.R.; Jaffrey, S.R. Local translation of RhoA regulates growth cone collapse. Nature 2005, 436, 1020-1024. [CrossRef]

15. Threadgill, R.; Bobb, K.; Ghosh, A. Regulation of dendritic growth and remodeling by Rho, Rac, and Cdc42. Neuron 1997, 19, 625-634. [CrossRef]

16. Hall, A. Rho GTPases and the actin cytoskeleton. Science 1998, 279, 509-514. [CrossRef] 
17. Cowan, C.W.; Shao, Y.R.; Sahin, M.; Shamah, S.M.; Lin, M.Z.; Greer, P.L.; Gao, S.; Griffith, E.C.; Brugge, J.S.; Greenberg, M.E. Vav family GEFs link activated Ephs to endocytosis and axon guidance. Neuron 2005, 46, 205-217. [CrossRef]

18. Faissner, A.; Kruse, J. J1/tenascin is a repulsive substrate for central nervous system neurons. Neuron 1990, 5, 627-637. [CrossRef]

19. Moritz, S.; Lehmann, S.; Faissner, A.; Holst, A. An induction gene trap screen in neural stem cells reveals an instructive function of the niche and identifies the splicing regulator sam68 as a tenascin-C-regulated target gene. Stem Cells 2008, 26, 2321-2331. [CrossRef]

20. Quevedo, C.; Sauzeau, V.; Menacho-Marquez, M.; Castro-Castro, A.; Bustelo, X.R. Vav3-deficient mice exhibit a transient delay in cerebellar development. Mol. Biol. Cell 2010, 21, 1125-1139. [CrossRef]

21. Menacho-Márquez, M.; Nogueiras, R.; Fabbiano, S.; Sauzeau, V.; Al-Massadi, O.; Diéguez, C.; Bustelo, X.R. Chronic sympathoexcitation through loss of Vav3, a Rac1 activator, results in divergent effects on metabolic syndrome and obesity depending on diet. Cell Metab. 2013, 18, 199-211. [CrossRef] [PubMed]

22. Sauzeau, V.; Horta-Junior, J.A.; Riolobos, A.S.; Fernandez, G.; Sevilla, M.A.; Lopez, D.E.; Montero, M.J.; Rico, B.; Bustelo, X.R. Vav3 is involved in GABAergic axon guidance events important for the proper function of brainstem neurons controlling cardiovascular, respiratory, and renal parameters. Mol. Biol. Cell. 2010, 21, 4251-4263. [CrossRef] [PubMed]

23. Perretta-Tejedor, N.; Fernández-Mateos, J.; García-Ortiz, L.; Gómez-Marcos, M.A.; Recio-Rodríguez, J.I.; Agudo-Conde, C.; Rodriguez-Sánchez, E.; Morales, A.I.; López-Hernández, F.J.; López-Novoa, J.M.; et al. Association of VAV2 and VAV3 polymorphisms with cardiovascular risk factors. Sci. Rep. 2017, 7, 41875. [CrossRef] [PubMed]

24. Aleksic, B.; Kushima, I.; Hashimoto, R.; Ohi, K.; Ikeda, M.; Yoshimi, A.; Nakamura, Y.; Ito, Y.; Okochi, T.; Fukuo, Y.; et al. Analysis of the VAV3 as candidate gene for schizophrenia: Evidences from voxel-based morphometry and mutation screening. Schizophr. Bull. 2013, 39, 720-728. [CrossRef] [PubMed]

25. Allen Mouse Brain Atlas. Allen Insitute for Brain Science. Available online: http://mouse.brain-map.org (accessed on 14 January 2020).

26. Lein, E.S.; Hawrylycz, M.J.; Ao, N.; Ayres, M.; Bensinger, A.; Bernard, A.; Boe, A.F.; Boguski, M.S.; Brockway, K.S.; Byrnes, E.J.; et al. Genome-wide atlas of gene expression in the adult mouse brain. Nature 2007, 445, 168-176. [CrossRef]

27. Zhang, Y.; Chen, K.; Sloan, S.A.; Bennett, M.L.; Scholze, A.R.; O’Keeffe, S.; Phatnani, H.P.; Guarnieri, P.; Caneda, C.; Ruderisch, N.; et al. An RNA-sequencing transcriptome and splicing database of glia, neurons, and vascular cells of the cerebral cortex. J. Neurosci. 2014, 34, 11929-11947. [CrossRef]

28. Dzyubenko, E.; Rozenberg, A.; Hermann, D.M.; Faissner, A. Colocalization of synapse marker proteins evaluated by STED-microscopy reveals patterns of neuronal synapse distribution in vitro. J. Neurosci. Methods 2016, 273, 149-159. [CrossRef]

29. Gottschling, C.; Dzyubenko, E.; Geissler, M.; Faissner, A. The Indirect Neuron-astrocyte Coculture Assay: An In Vitro Set-up for the Detailed Investigation of Neuron-glia Interactions. J. Vis. Exp. 2016, 117, e54757. [CrossRef]

30. Gottschling, C.; Geissler, M.; Springer, G.; Wolf, R.; Juckel, G.; Faissner, A. First and second generation antipsychotics differentially affect structural and functional properties of rat hippocampal neuron synapses. Neuroscience 2016, 337, 117-130. [CrossRef]

31. Dzyubenko, E.; Juckel, G.; Faissner, A. The antipsychotic drugs olanzapine and haloperidol modify network connectivity and spontaneous activity of neural networks in vitro. Sci. Rep 2017, 7, 11609. [CrossRef]

32. Geissler, M.; Faissner, A. A new indirect co-culture set up of mouse hippocampal neurons and cortical astrocytes on microelectrode arrays. J. Neurosci. Methods 2012, 204, 262-272. [CrossRef] [PubMed]

33. Caceres, A.; Banker, G.; Steward, O.; Binder, L.; Payne, M. MAP2 is localized to the dendrites of hippocampal neurons which develop in culture. Brain Res. 1984, 315, 314-318. [CrossRef]

34. Binder, L.I.; Frankfurter, A.; Rebhun, L.I. The distribution of tau in the mammalian central nervous system. J. Cell Biol. 1985, 101, 1371-1378. [CrossRef]

35. Pyka, M.; Busse, C.; Seidenbecher, C.; Gundelfinger, E.D.; Faissner, A. Astrocytes are crucial for survival and maturation of embryonic hippocampal neurons in a neuron-glia cell-insert coculture assay. Synapse 2011, 65, 41-53. [CrossRef] [PubMed] 
36. Canepari, M.; Bove, M.; Maeda, E.; Cappello, M.; Kawana, A. Experimental analysis of neuronal dynamics in cultured cortical networks and transitions between different patterns of activity. Biol. Cybern. 1997, 77, 153-162. [CrossRef] [PubMed]

37. Segev, R.; Shapira, Y.; Benveniste, M.; Ben-Jacob, E. Observations and modeling of synchronized bursting in two-dimensional neural networks. Phys. Rev. E Stat. Nonlin Soft Matter Phys. 2001, 64, 011920. [CrossRef] [PubMed]

38. Ulc, A.; Zeug, A.; Bauch, J.; van Leeuwen, S.; Kuhlmann, T.; Ffrench-Constant, C.; Ponimaskin, E.; Faissner, A. The guanine nucleotide exchange factor Vav3 modulates oligodendrocyte precursor differentiation and supports remyelination in white matter lesions. Glia 2019, 67, 376-392. [CrossRef]

39. Hale, C.F.; Dietz, K.C.; Varela, J.A.; Wood, C.B.; Zirlin, B.C.; Leverich, L.S.; Greene, R.W.; Cowan, C.W. Essential role for vav Guanine nucleotide exchange factors in brain-derived neurotrophic factor-induced dendritic spine growth and synapse plasticity. J. Neurosci. 2011, 31, 12426-12436. [CrossRef]

40. Aletta, J.M.; Greene, L.A. Growth cone configuration and advance: A time-lapse study using video-enhanced differential interference contrast microscopy. J. Neurosci. 1988, 8, 1425-1435. [CrossRef]

41. Ridley, A.J.; Hall, A. The small GTP-binding protein rho regulates the assembly of focal adhesions and actin stress fibers in response to growth factors. Cell 1992, 70, 389-399. [CrossRef]

42. Kozma, R.; Sarner, S.; Ahmed, S.; Lim, L. Rho family GTPases and neuronal growth cone remodelling: Relationship between increased complexity induced by Cdc42Hs, Rac1, and acetylcholine and collapse induced by RhoA and lysophosphatidic acid. Mol. Cell. Biol. 1997, 17, 1201-1211. [CrossRef] [PubMed]

43. Kranenburg, O.; Poland, M.; van Horck, F.P.; Drechsel, D.; Hall, A.; Moolenaar, W.H. Activation of RhoA by lysophosphatidic acid and Galpha12/13 subunits in neuronal cells: Induction of neurite retraction. Mol. Biol. Cell 1999, 10, 1851-1857. [CrossRef] [PubMed]

44. Takeuchi, S.; Katoh, H.; Negishi, M. Eph/ephrin reverse signalling induces axonal retraction through RhoA/ROCK pathway. J. Biochem. 2015, 158, 245-252. [CrossRef] [PubMed]

45. Jin, Z.; Strittmatter, S.M. Rac1 mediates collapsin-1-induced growth cone collapse. J. Neurosci. 1997, 17, 6256-6263. [CrossRef]

46. Joester, A.; Faissner, A. The structure and function of tenascins in the nervous system. Matrix Biol. 2001, 20, 13-22. [CrossRef]

47. Nakayama, A.Y.; Harms, M.B.; Luo, L. Small GTPases Rac and Rho in the maintenance of dendritic spines and branches in hippocampal pyramidal neurons. J. Neurosci. 2000, 20, 5329-5338. [CrossRef] [PubMed]

48. Ahnert-Hilger, G.; Höltje, M.; Grosse, G.; Pickert, G.; Mucke, C.; Nixdorf-Bergweiler, B.; Boquet, P.; Hofmann, F.; Just, I. Differential effects of Rho GTPases on axonal and dendritic development in hippocampal neurones. J. Neurochem. 2004, 90, 9-18. [CrossRef]

49. Luo, L.; Hensch, T.K.; Ackerman, L.; Barbel, S.; Jan, L.Y.; Jan, Y.N. Differential effects of the Rac GTPase on Purkinje cell axons and dendritic trunks and spines. Nature 1996, 379, 837-840. [CrossRef]

50. Tashiro, A.; Minden, A.; Yuste, R. Regulation of dendritic spine morphology by the rho family of small GTPases: Antagonistic roles of Rac and Rho. Cerebral Cortex 2000, 10, 927-938. [CrossRef]

51. Tashiro, A.; Yuste, R. Regulation of dendritic spine motility and stability by Rac1 and Rho kinase: Evidence for two forms of spine motility. Mol. Cell. Neurosci. 2004, 26, 429-440. [CrossRef]

52. Niftullayev, S.; Lamarche-Vane, N. Regulators of Rho GTPases in the Nervous System: Molecular Implication in Axon Guidance and Neurological Disorders. Int. J. Mol. Sci. 2019, 20, 1497. [CrossRef] [PubMed]

53. O'Kane, E.M.; Stone, T.W.; Morris, B.J. Increased long-term potentiation in the CA1 region of rat hippocampus via modulation of GTPase signalling or inhibition of Rho kinase. Neuropharmacology 2004, 46, 879-887. [CrossRef] [PubMed]

54. Diana, G.; Valentini, G.; Travaglione, S.; Falzano, L.; Pieri, M.; Zona, C.; Meschini, S.; Fabbri, A.; Fiorentini, C. Enhancement of learning and memory after activation of cerebral Rho GTPases. Proc. Natl. Acad. Sci. USA 2007, 104, 636-641. [CrossRef] [PubMed]

55. McMullan, R.; Hiley, E.; Morrison, P.; Nurrish, S.J. Rho is a presynaptic activator of neurotransmitter release at pre-existing synapses in C. elegans. Genes Dev. 2006, 20, 65-76. [CrossRef]

56. Isaac, J.T.; Nicoll, R.A.; Malenka, R.C. Evidence for silent synapses: Implications for the expression of LTP. Neuron 1995, 15, 427-434. [CrossRef]

57. Kerchner, G.A.; Nicoll, R.A. Silent synapses and the emergence of a postsynaptic mechanism for LTP. Nat. Rev. Neurosci. 2008, 9, 813-825. [CrossRef] 
58. Nakano-Kobayashi, A.; Kasri, N.N.; Newey, S.E.; Van Aelst, L. The Rho-linked mental retardation protein OPHN1 controls synaptic vesicle endocytosis via endophilin A1. Curr. Biol. 2009, 19, 1133-1139. [CrossRef]

59. Hamdan, F.F.; Gauthier, J.; Spiegelman, D.; Noreau, A.; Yang, Y.; Pellerin, S.; Dobrzeniecka, S.; Cote, M.; Perreau-Linck, E.; Carmant, L.; et al. Mutations in SYNGAP1 in autosomal nonsyndromic mental retardation. N. Engl. J. Med. 2009, 360, 599-605. [CrossRef]

60. Giannandrea, M.; Bianchi, V.; Mignogna, M.L.; Sirri, A.; Carrabino, S.; D’Elia, E.; Vecellio, M.; Russo, S.; Cogliati, F.; Larizza, L.; et al. Mutations in the small GTPase gene RAB39B are responsible for X-linked mental retardation associated with autism, epilepsy, and macrocephaly. Am. J. Hum. Genet. 2010, 86, 185-195. [CrossRef]

61. Rossman, K.L.; Der, C.J.; Sondek, J. GEF means go: Turning on RHO GTPases with guanine nucleotide-exchange factors. Nat. Rev. Mol. Cell Biol. 2005, 6, 167-180. [CrossRef]

62. Cho, H.J.; Kim, J.T.; Baek, K.E.; Kim, B.Y.; Lee, H.G. Regulation of Rho GTPases by RhoGDIs in Human Cancers. Cells 2019, 8, 1037. [CrossRef]

63. Schmitter, T.; Pils, S.; Sakk, V.; Frank, R.; Fischer, K.D.; Hauck, C.R. The granulocyte receptor carcinoembryonic antigen-related cell adhesion molecule 3 (CEACAM3) directly associates with Vav to promote phagocytosis of human pathogens. J. Immunol. 2007, 178, 3797-3805. [CrossRef]

64. Breitinger, C.; Maethner, E.; Garcia-Cuellar, M.P.; Schambony, A.; Fischer, K.D.; Schilling, K.; Slany, R.K. HOX genes regulate Rac1 activity in hematopoietic cells through control of Vav2 expression. Leukemia 2013, 27, 236-238. [CrossRef] [PubMed]

65. Gwak, S.-J.; Macks, C.; Jeong, D.U.; Kindy, M.; Lynn, M.; Webb, K.; Lee, J.S. RhoA knockdown by cationic amphiphilic copolymer/siRhoA polyplexes enhances axonal regeneration in rat spinal cord injury model. Biomaterials 2017, 121, 155-166. [CrossRef] [PubMed]

66. Devaux, S.; Cizkova, D.; Mallah, K.; Karnoub, M.A.; Laouby, Z.; Kobeissy, F.; Blasko, J.; Nataf, S.; Pays, L.; Mériaux, C.; et al. RhoA Inhibitor Treatment At Acute Phase of Spinal Cord Injury May Induce Neurite Outgrowth and Synaptogenesis. Mol. Cell. Proteom. 2017, 16, 1394-1415. [CrossRef]

67. Hu, J.; Selzer, M.E. RhoA as a target to promote neuronal survival and axon regeneration. Neural Regen. Res. 2017, 12, 525-528.

68. Yang, Z.; Wang, J.; Liu, X.; Cheng, Y.; Deng, L.; Zhong, Y. Y-39983 downregulates RhoA/Rho-associated kinase expression during its promotion of axonal regeneration. Oncol. Rep. 2013, 29, 1140-1146. [CrossRef]

69. Fu, Q.; Hue, J.; Li, S. Nonsteroidal anti-inflammatory drugs promote axon regeneration via RhoA inhibition. J. Neurosci. 2007, 27, 4154-4164. [CrossRef]

70. Luft, V.; Reinhard, J.; Shibuya, M.; Fischer, K.D.; Faissner, A. The guanine nucleotide exchange factor Vav3 regulates differentiation of progenitor cells in the developing mouse retina. Cell Tissue Res. 2015, 359, 423-440. [CrossRef]

71. Keilhoff, G.; Wiegand, S.; Fansa, H. Vav deficiency impedes peripheral nerve regeneration in mice. Restor. Neurol. Neurosci. 2012, 30, 463-479. [CrossRef]

72. Tedford, K.; Nitschke, L.; Girkontaite, I.; Charlesworth, A.; Chan, G.; Sakk, V.; Barbacid, M.; Fischer, K.D. Compensation between Vav-1 and Vav-2 in B cell development and antigen receptor signaling. Nat. Immunol. 2001, 2, 548-555. [CrossRef] [PubMed]

73. Geissler, M.; Gottschling, C.; Aguado, A.; Rauch, U.; Wetzel, C.H.; Hatt, H.; Faissner, A. Primary hippocampal neurons, which lack four crucial extracellular matrix molecules, display abnormalities of synaptic structure and function and severe deficits in perineuronal net formation. J. Neurosci. 2013, 33, 7742-7755. [CrossRef] [PubMed]

74. Pyka, M.; Wetzel, C.; Aguado, A.; Geissler, M.; Hatt, H.; Faissner, A. Chondroitin sulfate proteoglycans regulate astrocyte-dependent synaptogenesis and modulate synaptic activity in primary embryonic hippocampal neurons. Eur. J. Neurosci. 2011, 33, 2187-2202. [CrossRef] [PubMed]

(C) 2020 by the authors. Licensee MDPI, Basel, Switzerland. This article is an open access article distributed under the terms and conditions of the Creative Commons Attribution (CC BY) license (http://creativecommons.org/licenses/by/4.0/). 